\title{
Penile Neoplasm
}

National Cancer Institute

\section{Source}

National Cancer Institute. Penile Neoplasm. NCI Thesaurus. Code C3317.

A benign, borderline, or malignant neoplasm that affects the penis. Representative examples include penile hemangioma, penile intraepithelial neoplasia, and penile carcinoma. 